A list of Working Papers on the last pages

No. 272,1990

COMPARATIVE ADVANTAGE, TERMS OF TRADE AND WELFARE EFFECTS OF EUROPEAN INTEGRATION: Some preliminary assessments

by

Jan I. Haaland

Paper presented at the IUI/NEF Workshop on The EC Internal Market and the Nordic Countries, June 11-13, 1990, at Lidingö, Sweden 


\title{
Comparative advantage, terms of trade and welfare effects of European integration: \\ Some preliminary assessments.
}

by

Jan I. Haaland 0

\begin{abstract}
:
The paper presents a first attempt at assessing general equilibrium effects of 1992. Two kinds of general equilibrium effects are relevant: one (dampening) effect stemming from the common resource constraints, the other one related to the fact that the relative competitiveness of industries may be altered as a consequence of the integration. This paper focuses on the second type of general equilibrium effects, and the results show that there may be additional gains for the EC stemming from terms-oftrade improvements and reduced dependence on subsidized and protected industries. The paper also presents general equilibrium assessments for Norway, under various assumptions regarding Norwegian participation in the integration process.
\end{abstract}

February 1990

Revised September 1990

Norwegian School of Economics and Business Administration

Bergen, Norway

0 I would like to thank Victor Norman, Linda Orvedal, Geir-Helge Sjøtrø, Siri P. Strandenes and participants at at the workshop "The EC integration and the Nordic countries" in Stockholm in June 1990 for comments and discussions. Some of the results from this paper are also presented in Haaland (1990). 


\section{Introduction}

Although the 1992-programme is a policy change of a kind that is supposed to affect many markets simultaneously and as such calls for general equilibrium assessments, most of the quantitative analyses of the internal market have been performed in a partial equilibrium framework. There are many reasons for this - the most important one is probably that there as yet do not exist general equilibrium models that incorporate the type of trade theory that is used in the partial equilibrium models. Most existing computable general equilibrium (CGE) models of international trade are based on theory of comparative advantage with perfect competition and constant retums to scale. All the studies of the effects of 1992, on the other hand, are based on theory of intra-industry trade with economies of scale, product differentiation and imperfect competition as the main ingredients.

The advantage of a partial equilibrium approach is that one can grasp the characteristics of each market in some detail ${ }^{1}$. As the number of firms, the type of competition, the degree of scale economies and the degree of product differentiation are important factors in the analysis of such markets, it seems inconceivable to look at more than one market at the time. And since this type of trade theory - contrary to comparative advantage theory - explains trade and welfare effects within one industry, there has been no need to develop the theoretical framework for general equilibrium analysis along this avenue.

This does not, however, imply that the general equilibrium effects of the 1992-programme are not important. The programme is supposed to affect all types of markets and there must be implications for relative prices and for wages, rates of return to capital and so on. And in particular, if the programme affects some markets more than others, there will be implicit comparative advantage and terms-of-trade effects both within the EC and vis-à-vis the rest of the world.

Two kinds of general equilibrium effects are relevant: One stemming from the common resource constraints, the other one related to the fact that the relative competitiveness of industries may be altered as a consequence of the integration. These effects are, of course, not independent of each other; in particular the possible changes in comparative advantages are not relevant unless there are binding resource constraints; it is nevertheless instructive to think of these as separate effects.

Binding resource constraints imply that the total welfare effect is different from the sum of the partial equilibrium assessments - it is impossible to expand all types of production simultaneously. Norman (1989a) constructs a small-scale, general equilibrium model of trade with imperfectly competitive markets, and shows how general

1 The best examples of partial equilibrium analyses of EC-intergration are those in Smith and Venables (1988). Similar studies, including the Scandinavian countries, are presented in Norman (1989a). 
equilibrium repercussions could dampen the effects from partial equilibrium models in the EC - EFTA framework. However, his model does not include possible developments in comparative advantages in a proper way; and - perhaps more important - trade with the rest of the world is kept constant.

In this paper, I will look at the second set of general equilibrium effects, by focusing on comparative advantage and terms-of-trade effects of European integration. To do this properly one would have needed a CGE-model of world trade with imperfect competition. However, Norman (1989b) shows that although imperfect competition may dampen general equilibrium responses, the qualitative conclusions are not altered; hence, I will try to assess some types of general equilibrium effects using models with perfect competition. For this purpose I will apply two models: VEMOD which is a CGE-model for world trade, and HOVMOD which is a model for Norway, modelled as a small, open economy. The models have the same structure, and are both very closely based on comparative advantage theory. In analysing the situation for Norway, the two models are used in tandem: VEMOD is used to assess world market prices, whereas HOVMOD "translates" these prices into production and trade effects for Norway.

Models with perfect competition and constant returns to scale can obviously not catch all the effects of EC-integration. In particular, the direct gains can not be captured endogenously. In addition it should be emphasized that the structural flexibility and the accompanying welfare effects may be exaggerated due to perfectly competitive markets and a high degree of factor mobility between industries. The models may nevertheless give some insights that have so far been ignored, and in this paper I will focus on these additional insights rather than presenting model results in any detail.

For Norway with very much of the production and exports in industries with homogeneous products and close to perfect competition (see Haaland (1990)), the general equilibrium effects of 1992 may be particularly important, and the total effects thus cannot be assessed without a general equilibrium framework.

In the world trade model VEMOD the EC is one region, with common supply and demand functions for traded goods, a common market for non-traded goods, common factor markets, etc.; hence, in the model the internal market is already completed, implying that we cannot endogenously compute the direct effects of 1992. However, since the purpose is to analyse general equilibrium repercussions and to look at effects on the external relations for the EC, we can take the direct "partial equilibrium effects" from other sources, and impose those effects as exogenous shocks in the model.

The combined effects of the expected market changes in the EC-markets can to a great extent be interpreted as a cost reduction or a productivity improvement within the EC. This comes in part as true cost reductions through rationalization and economies of scale, 
and in part as reduced price/cost-margins due to stronger competition. The overall effects for terms of trade and comparative advantages are under certain assumptions similar to what one could expect from productivity improvements in the EC; thus, in the model experiments reported here, 1992 will be modelled as exogenous productivity shocks.

The dampening effect of binding resource constraints is to some extent avoided when the integration is modelled as productivity improvements. It is possible to have growth in all sectors simultaneously in the simulations; this may reflect the fact that real resources are freed in the integration process, or there may be idle resources in Europe initially. The general equilibrium effects of 1992, modelled as productivity improvements, depend very much on how the total effects are distributed between sectors. If the impact is equally strong on all types of production, one could probably expect increased overall production and welfare in the EC with limited implications for the pattern of production and for relative goods and factor prices. If, on the other hand, the expected impact is stronger for some types of production than for others, then the comparative advantage position of the EC may be altered, and there may be important general equilibrium effects through changes in the pattern of production and external trade, changes in relative factor prices and changes in world market prices and the terms of trade. The gains reported in Emerson (1988) (see also section 5, below) are far from equally distributed between industries; consequently, one should expect changes to occur in the external trade position of the EC, and these effects have implications not only for the EC, but equally much for the rest of the world. Furthermore, any change in the external trade policy or in the industrial policy of the EC may in a similar way affect world markets.

The plan for the rest of the paper is first to sketch the structure of the two models applied. In sction 3 it is shown how the expected general equilibrium effects of 1992 can be captured in models with perfectly competitive markets. Then I will discuss briefly the specification of the scenarios we study, and finally the results will be presented, first for the major world regions from the world trade model VEMOD, with emphasis on the effects for the EC and EFTA, and then for Norway from the small, open economy model HOVMOD.

\section{The models}

For a discussion of the modelling approach applied in the two models as well as detailed descriptions of the model structures, see Haaland et al (1987), Haaland and Norman (1987) and Haaland (1989). Here I will only sketch the most important parts of the theoretical basis and the model structures. The two models are very similar; the only important difference is that in VEMOD several world regions are modelled, and world market conditions are determined endogenously through the interaction between 
the regions, whereas in HOVMOD world market conditions are given exogenously, and Norway adjusts production and trade in accordance with these conditions.

VEMOD and HOVMOD are based on standard trade theory. The pattern of production and trade is assumed to reflect comparative advantage, which in turn derives from differences in endowments of intersectorally mobile (but internationally immobile) factors of production, differences in the supply of sector-specific factors, or technological differences - i.e. differences in the relative ability to produce different goods. This pattern will, however, be distorted by tariffs, subsidies, or other forms of trade policies.

A simplified version of the model VEMOD is shown in equations (1) - (3). The actual model have a number of special features in addition to this, but the principles are the same. Optimum production in constant returns to scale industries with perfect competition is determined from a set of complementarity conditions:

$$
a_{i}^{r} b_{i}^{r}\left(w^{r}\right) \geq p_{i}^{r} \quad x_{i}^{T} \geq 0, \quad i=1, \ldots, N
$$

where $\mathrm{p}_{\mathrm{i}}^{\mathrm{r}}$ is the producer price for good $\mathrm{i}$ in region $\mathrm{r}$ (which again is equal to world market price adjusted for tariffs or subsidies, e.g. $\mathrm{p}_{\mathrm{i}}^{\mathrm{r}}=\mathrm{P}_{\mathrm{i}}\left(1+\mathrm{s}_{\mathrm{i}}^{r}\right)$ if $\mathrm{P}_{\mathrm{i}}$ is the world market price, and $s_{i}^{r}$ is a summary measure of all trade and industrial policies in the region). $\mathbf{x}_{i}^{r}$ is output of good $i$ in the region, and $w^{r}$ is a vector of domestic factor prices. $a_{1}^{r} b_{i}^{T}\left(w^{r}\right)$ is the of unit cost function, where $a_{i}^{r}$ is a productivity parameter. The productivity parameters are introduced for convenience, since we are going to focus on productivity changes; $\mathrm{da}_{\mathrm{i}}^{\mathrm{r}}<0$ implies improved productivity. (1) is a standard formulation of optimum production at given prices.

Factor market equilibrium is given by the following set of conditions:

$$
\sum_{i=1}^{N} a_{i}^{r} \frac{\partial b_{i}^{r}\left(w^{r}\right)}{\partial w_{j}^{r}} x_{i}^{r} \leq v_{j}^{r} \quad w_{j}^{r} \geq 0, \quad j=1, . ., M,
$$

where $v^{r}=\left(v_{1}^{r}, \ldots, v_{M}^{r}\right)$ is the vector of (given) factor endowments. For a given vector of goods prices, (1) and (2) determine the output-vector, $\mathbf{x}^{\mathbf{r}}$, and the vector of factor prices, $w^{\mathbf{r}}$. Finally, in a world trade model we need equations for world market equilibria:

$$
\sum_{r=1}^{R} x^{r} \geq \sum_{r=1}^{R} c^{r} \quad P \geq 0
$$

where $c^{r}$ is the vector of consumption in region $r$ (stemming again from some kind of optimum consumer behaviour), and $\mathrm{R}$ is the number of regions. $\mathrm{P}$ is the vector of 
world market prices.

\subsection{Model structure - VEMOD}

There are six world regions in VEMOD:

- EC

- EFTA

- USA, Canada and Australia (called, somewhat misleadingly, North America)

- Japan

- Hong Kong, Singapore, South Korea, Mexico, Brazil and Argentina (called newly industrialized countries, or NIC)

- Other market economies (LDC)

Eastern Europe, the USSR, and China are not included in the model. They are excluded mainly because we lack reliable data; an additional rationale is that their trade has so far been governed by non-market forces. Given current trade flows, the exclusion of socialist countries is probably not very important. With the recent political development in Eastern Europe, the region could, however, be important for world trade over the long-term period for which the model is used.

The analysis is carried out at a very high level of aggregation. We identify five primary factors; capital, two types of labour (skilled and unskilled), energy resources and raw material resources. These are used as inputs in the production of five traded goods; viz. oil, raw materials (including agricultural products), and three types of manufactured goods - high-tech (skill-intensive), labour-intensive, and capital-intensive goods. In addition, each region has a non-traded sector which largely produces services ${ }^{2}$. The high level of aggregation is chosen because of the difficulties involved in identifying sources of comparative advantage at a more detailed level of commodity classifications. As the theory relates comparative advantage to the input characteristics of goods, it is natural to use input characteristics as a key classification criterion.

As input characteristics may change over the product cycle, the model-goods should not be related too closely to specific types of products - it is more correct to see them as activities available for production. In benchmarking the model, however, we have defined the goods as aggregates of production according to standard ISIC classifications. This classification is given in the appendix.

A word of caution is appropriate in relation to the concept of high-tech production. By this term, we mean production of goods which use skilled labour intensively. Examples of such goods are engineering products and chemical and pharmaceutical products. High-tech production in this sense should not be confused with the use of

2 For non-traded goods there are of course market clearing conditions similar to (3) for each region, not for the world market as a whole. 
best-practice technology in production. We take for granted that producers of all goods use the best technology available to them; and in the simulations there are important international differences in this "best available" technology.

Over time, the pattern of comparative advantage will change as relative factor endowments and available technology change. In the model simulations, such changes are largely exogenous. The rates of technical progress, for different countries and goods, must be specified exogenously; the same is true for growth in the labour force and changes in its educational composition. As regards capital accumulation, we are only slightly more sophisticated: Savings rates must be specified exogenously; but the model solves for the future capital stocks that follow.

The model is solved as sequences of static, general equilibria. Each static equilibrium is a straightforward application of well-known comparative advantage theories, as indicated above. Each region has given endowments of primary factors and is a potential producer of six goods - one non-tradeable and the five tradeable aggregates. The growth process is generated by a putty-clay model. As the purpose of the model is to produce scenarios for future production patterns, only the static equilibrium for the final year is reported.

We make an important distinction between capital equipment in place in our benchmark year (extant capital) and accumulated gross saving from the benchmark to the solution year (new-vintage capital). The former is assumed to be sector-specific, and to embody inflexible, existing technology. The latter is assumed to be fully mobile across domestic production sectors, and to embody new, more flexible technology. The longer the time horizon, the more new-vintage, flexible capital will dominate.

Details about production and demand are given in Haaland et al (1987). Here it suffices to mention a few points. Due to the putty-clay assumption (with two vintages) there are two production processes for each good in each region - one using extant capital, the other one new-vintage capital. Hence, for each good there are two complementarity conditions like (1), and we typically assume that the cost function for new-vinatge production is more flexible and have higher productivity than production using extant capital. Since extant capital is sector specific there may nevertheless be room for positive production with both technologies. In addition there may be pure endowments of goods; this is used to capture low-cost supplies of oil. Total production of a good in a region is then the sum of extant and new-vintage production, plus initial endowments, if any. All production functions are two-level CES-functions, with, typically, a much higher elasticity of substitution between factors in new-vintage than in extant production.

Intermediate inputs are not modelled explicitly; production is defined in value-added terms. There is one exception - the use of raw materials and oil as inputs is modelled 
explicitly. Hence, oil and raw materials are used both as inputs and for final demand (consumption and investment) purposes; other goods are only used for final demand purposes.

There are decreasing returns to scale with regard to the mobile factors ${ }^{3}$ in oil and raw material production, and constant returns to scale in all other production. There is perfect competition in all goods and factor markets, and goods from different regions are perfect substitutes (i.e. no Armington assumption). The static model is in equilibrium when all world goods markets, and all domestic markets for factors and goods clear in all regions. There are no endogenous international factor movements, hence all primary factors are non-traded.

\subsection{Dynamics and factor supply}

Factor endowments, productivity, and economic policy may change from one static equilibrium to the next. The development in the capital stock is probably the most interesting one, since old and new capital have different properties. Extant capital is assumed to comprise all capital present in our benchmark-year. All investments (which in the model are generated by a constant, exogenously specified savings rate) made between the benchmark-year and the final solution year is of the new-vintage type. Since new-vintage capital is intersectorally mobile, while extant capital is not, this implies that not only net investment rates but also gross investments are of importance for the future production pattern. Extant capital changes over time, partly because of physical depreciation (at constant, exogenous depreciation rates), and partly as a result of economic obsolescence (non-positive quasi-rents).

Other factors develop in accordance with exogenously given growth rates. Hicksneutral technological development takes place as a result of exogenously specified annual productivity growth rates. The productivity level and development may differ between extant and new-vintage production - a feature which makes it possible to model embodied technical improvements. In this way the gross investment rate becomes even more important.

The structure of HOVMOD is very similar, the differences are that the traded goods prices are exogenously given (taken from VEMOD) and that there are two non-traded sectors: A sheltered private sector and a public sector. The demand for public goods is exogenously specified; in the scenarios presented here, it follows the growth in GDP.

3 The model implicitly calibrates endowments of sector-specific resources in these sectors, and there are constant retums to scale with regard to all factors (including the sector-specific ones). 


\section{1992 as productivity improvements}

In this section I will show how under certain assumptions it is possible to model the general equilibrium effects of 1992 as productivity improvements. I will do that by showing how long-run equilibrium in imperfectly competitive markets may have a similar structure, and, more importantly, similar general equilibrium properties as in the model described in (1) - (3) above.

The 1992-programme is to a large extent concerned with the situation in imperfectly competitive industries. Let us assume that the total cost function for a firm in industry $i$ in region $\mathrm{r}$ can be written

$$
c_{i}^{c}\left(w^{r}, z_{i}^{r}\right)=h_{i}^{r}\left(z_{i}^{r}\right) b_{i}^{r}\left(w^{r}\right)
$$

where $z_{i}^{r}$ is the output of a representative firm in industry $i$, and the $h$-function takes care of the increaing economies of scale, if any. If there are $\mathrm{n}_{\mathrm{i}}^{\mathrm{r}}$ firms, the total supply of good $\mathrm{i}$ in this region is $x_{i}^{r}=n_{i}^{r} z_{i}^{r}$. Prices in imperfectly competitive industries can typically be written as a mark-up over marginal costs, i.e.:

$$
p_{i}^{r}=m_{i}^{r} \frac{\partial h_{i}^{T}\left(z_{i}^{r}\right)}{\partial z_{i}^{r}} b_{i}^{I}\left(w^{r}\right)
$$

where $\mathrm{m}_{\mathrm{i}}^{\mathrm{r}}$ is a mark-up factor that may depend on the number of firms, the type of competition and so on. Total output from the industry depends on output dicisions in each firm and on the criterion for entry or exit of firms. In a long run perspective an endogenous number of firms determined from a zero-profit condition is the most common assumption; hence the equilibrium must also satisfy

$$
p_{i}^{\mathrm{T}}=\frac{h_{i}^{\mathrm{T}}\left(\mathrm{z}_{\mathrm{i}}^{\mathrm{T}}\right)}{\mathrm{z}_{\mathrm{i}}^{\mathrm{T}}} b_{\mathrm{i}}^{\mathrm{T}}\left(\mathbf{w}^{\mathrm{T}}\right)
$$

In the partial equilibrium analyses of 1992-programme (see e.g. Smith and Venables (1988) and Norman (1989a)) the most important gains are related to increased exploitation of economies of scale and reduced mark-ups through stronger (international) competition. In long run equilibrium (6) must be satisfied in all industries; in such an equilibrium the total industry supply will be elastic in the sense that the number of firms, $\mathrm{n}_{\mathrm{i}}^{\mathrm{r}}$, adjusts to changing market conditions. But then, if we write

$$
a_{i}^{r}=\frac{h_{i}^{r}\left(z_{i}^{r}\right)}{z_{i}^{r}}=m_{i}^{r} \frac{\partial h_{i}^{r}\left(z_{i}^{r}\right)}{\partial z_{i}^{r}}
$$

and use $x_{i}^{r}=n_{i}^{r} z_{i}^{r}$, the structure is identical to the one in (1) and it should be clear that 
the types of general equilibrium effects and gains in this model are identical to the effects we get from productivity improvements in the perfectly competitive model in presented in equations (1) - (3) above.

The only important difference is that in the imperfectly competitive model the general equilibrium repercussions may have feedback effects on the exploitations of scale economies and mark-ups, while in the perfectly competitive framework the changes are coinsidered as exogenously given. Another difference may stem from different assumptions regarding product differentiation and market segmentation. In VEMOD goods are assumed to be homogeneous and there is one world market price for each good; models with imperfect competition often differ from these assumptions. In qualitative terms, however, the general equilibrium effects are the same in the perfectly competitive framework; and these general equilibrium effects, modelled as productivity improvements, are the central issues in this paper.

\section{A Reference scenario for the world economy}

The model VEMOD is applied to analyse the effects of European integration in a fairly long-term perspective. The time horizon is set to the year 2000 , implying that the 1992-programme is given some seven to eight years to work its way through the economies. This is in accordance with the time horizon indicated in Emerson (1988) for the most far-reaching effects to be relevant. "Comparative static" experiments representing various degrees of European integration and changes in industrial and external trade policies will be presented, with a reference scenario without integration as the basis for comparison.

The reference scenario has been constructed along the lines reported in Haaland and Norman (1987). The most important assumptions are: Labour force growth in accordance with ILO (1986) projections; savings rates close to recent historical averages; some growth in the skilled/unskilled labour ratio in the industrialized regions but not in the developing countries; uniform technological progress in all regions (stronger for production with new-vintage capital than for production with extant, sector-specific capital), no change in trade or industrial policies and no international capital flows in the solution year ${ }^{4}$. The industrial structure in the benchmark data (for 1979) and in the reference scenario are shown in table 1.

\footnotetext{
4 For details on the assumptions, see Haaland and Norman (1987). The only important difference is that I have reduced the capital depreciation rate in order to make extant, sector-specific capital more important in the solution year. This has been done to reduce the structural changes somewhat, reflecting that the policies we are going to study will take place in 1992, and not in the benchmark year (which is 1979).
} 
Table 1. Pattern of industrial production.

(Relative distribution of industrial value added.)

\begin{tabular}{|l|cc|cc|cc|}
\hline \multirow{4}{*}{ Sector } & EC & & \multicolumn{1}{|l|}{ EFTA } & & \multicolumn{2}{|c|}{ North America } \\
\cline { 2 - 7 } High-tech & Benchmark & Ref-2000 & Benchmark & Ref-2000 & Benchmark & Ref-2000 \\
Lab-int & 0.42 & 0.21 & 0.40 & 0.17 & 0.42 & 0.70 \\
Cap-int & 0.25 & 0.18 & 0.23 & 0.08 & 0.25 & 0.13 \\
\hline & 0.33 & 0.61 & 0.38 & 0.76 & 0.33 & 0.17 \\
\hline & Japan & & NIC & & LDC & \\
\cline { 2 - 8 } Sector & Benchmark & Ref-2000 & Benchmark & Ref-2000 & Benchmark & Ref-2000 \\
\hline High-tech & 0.43 & 0.82 & 0.39 & 0.13 & 0.32 & 0.11 \\
Lab-int & 0.27 & 0.07 & 0.38 & 0.79 & 0.36 & 0.77 \\
Cap-int & 0.30 & 0.11 & 0.23 & 0.08 & 0.32 & 0.12 \\
\hline
\end{tabular}

Compared to the benchmark data this shows a strong growth in the comparative advantage in high-tech production in North America, a strong comparative advantage in labour-intensive production in NICs and LDCs, and a strong comparative advantage in capital-intensive production in EFTA, all in accordance with the assumed development in factor endowments. For Japan there is apparently a comparative advantage in hightech production. However, the savings rate is very high for Japan, and in Haaland and Norman (1987) it was demonstrated that the structure for Japan is not robust; fairly small changes in market conditions may yield substantial changes the industrial structure towards more capital-intensive and less high-tech production. The European Community is the counterpart for these changes: if Japan switches towards more capital-intensive production, the high-tech sector will grow and the capital-intensive sector decline in the EC.

\section{Alternative scenarios}

Alternative scenarios representing various degrees of European integration and liberalization will be compared to the reference scenario. In this section integration takes place in the EC only; in the next section it is assumed that EFTA takes part in the process as well.

\section{Scenario 1: EC integration}

EC integration is modelled as productivity shifts, reflecting the gains calculated in partial equilibrium models. Emerson (1988) reports such calculations for several sectors. The gains are not equally distributed across sectors; they are typically stronger the more important economies of scale, product differentiation and imperfect competition are in the sectors. In terms of the VEMOD-sectors one would according to this expect the gains to be higher in the high-tech sector, and a rough aggregation of the industries reported in Emerson (1988) into the VEMOD-sectors confirms this assumption. The weighted average gain relative to production is approximately 7 per cent for the 
industries classified as high-tech industries, and approximately 2 per cent for each of the other traded industries. For non-traded goods and services there is also a gain of about 2 per cent.

Hence, in the EC-integration scenario the productivity parameter in the EC in the year 2000 is 7 per cent higher for high-tech production and 2 per cent higher for all other types of production than in the reference scenario. There are no other changes in the $\mathrm{EC}$, and no changes in the assumptions for any other regions.

\section{Scenario 2: EC-integration and reduced subsidies}

Subsidies and other types of industrial policies in the EC are probably applied in part for external trade reasons, and in part to keep industries alive for internal reasons, e.g. employment considerations in certain countries or regions. As a part of the 1992programme one should expect at least the latter kind of support to be reduced. This kind of support is often related to the industries classified as capital-intensive in VEMOD, and as a very moderate example of a reduction in industrial support, the producer prices (relative to the world market prices) in capital-intensive production in the EC are reduced by two per cent in this scenario 5 . Hence, the sceanrio is a combination of integration - as in the previous case - and reduced subsidies, and as we shall see below, the structural effects are substantial even with this moderate reduction, indicating that changes in the industrial policy may be important.

\section{Scenario 3: Liberalization in the EC}

As a final case, we look at a scenario in which in addition to the assumptions from the former case (i.e. integration and reduced subsidies to capital-intensive production) all external trade policies for the EC are reduced by 10 per cent. All trade policies in VEMOD are comprised into one measure, and specified as a production subsidy. Hence, a 10 per cent reduction means a reduction not only of tariffs, but of all kinds of tariff and non-tariff barriers. In our benchmark data and in the reference scenario, the barriers in the EC are strongest for raw-material and labour-intensive products, and weakest for high-tech products. A 10 per cent reduction for all sectors thus reinforces the advantage for the high-tech sector in the EC.

\subsection{Terms of trade and the pattern of production}

The effects for the pattern of production relative to the reference scenario are summarized in table 2. For North America, NICs and LDCs there are almost no effects on the structure of industry; hence, these regions are not included in the table. The table reveals that in all three cases the pattern of production in the EC is shifted towards more

5 This magnitude of reduction is completely arbitrarily chosen in the sense that it is not based on any information about planned changes in policies; however, it matches the productivity growth, implying that the capital-intensive sector in the EC is back to status quo, except for the general equilibrium effects in goods and factor markets. 
high-tech production and less capital-intensive production, in accordance with what one would expect. However, it is also clear that changes in the industrial and/or trade policies are necessary for the shift to be of any magnitude.

Table 2. The pattern of industrial production.

(Relative distribution of industrial value added.)

\begin{tabular}{|l|ccccc|}
\hline $\begin{array}{r}\text { Scenario } \\
\text { Regions and goods }\end{array}$ & Benchmark & $\begin{array}{c}\text { Reference } \\
2000\end{array}$ & $\begin{array}{c}\text { EC- } \\
\text { integration }\end{array}$ & $\begin{array}{c}\text { Reduced } \\
\text { subsidies }\end{array}$ & $\begin{array}{c}\text { Libera- } \\
\text { lization }\end{array}$ \\
\hline EC & & & & & \\
High-tech & 0.42 & 0.21 & 0.28 & 0.40 & 0.45 \\
Labour-intensive & 0.25 & 0.18 & 0.16 & 0.17 & 0.16 \\
Capital-intensive & 0.33 & 0.61 & 0.56 & 0.43 & 0.39 \\
\hline EFTA & & & & & \\
High-tech & 0.40 & 0.17 & 0.15 & 0.14 & 0.14 \\
Labour-intensive & 0.23 & 0.08 & 0.08 & 0.07 & 0.07 \\
Capital-intensive & 0.38 & 0.76 & 0.77 & 0.79 & 0.79 \\
\hline JAPAN & & & & & \\
High-tech & 0.43 & 0.82 & 0.74 & 0.47 & 0.38 \\
Labour-intensive & 0.27 & 0.07 & 0.08 & 0.07 & 0.08 \\
Capital-intensive & 0.30 & 0.11 & 0.18 & 0.45 & 0.55 \\
\hline
\end{tabular}

The patterns of production in EFTA and Japan change in the opposite direction, but for EFTA the effects are moderate, as the region is almost completely specialized in capitalintensive production at the outset. For Japan the flexibility is much greater, and as noted before, Japan is very close to having a comparative advantage in capital-intensive production in the reference scenario, due to the assumed strong growth in the capital/labour ratio in Japan.

The production and the accompanying trade effects vis-à-vis Japan, are probably the most important new insights from this table. The external trade effects of integration have not been properly analysed so far, but they may obviously be of importance. The shifts in the production and trade pattern may seem very strong, in particular in the last two scenarios. In part this is due to the perfectly competitive framework; imperfect competition would probably dampen the structural changes, but qualitatively the effects would not be altered. However, it is also worth noting that although the shifts are substantial, they do in fact move the production pattern for Europe back towards the initial situation. Hence, perhaps the 1992-programme should be seen as a prerequisite if the EC aims at maintaining a diversified structure of industry with a strong high-tech sector.

In the liberalization scenario one would probably have expected a substantial reduction in labour-intensive production in the EC. There are two reasons why this does not occur: First, most of the labour-intensive production in the EC in the reference scenario takes place using extant, sector-specific capital, so the flexibility is limited; and 
secondly, since the bulk of labour-intensive production in the world takes place in the two regions of developing countries, and these are close to being completely specialized (see table 1), there is little capacity for other regions to fill the gap if the EC reduces the supply of such goods 6 . Hence, the flexibility is limited and the price effects are strong, as is clear from table 3 . This point also illustrates the fact that there is a tradeoff between the terms-of-trade effects and the changes in the pattern of production and trade. The more flexible the production in the EC and in other regions is, the smaller the world market price effects will be.

Table 3. World market price effects, relative to the reference scenario. (High-tech is numeraire.)

\begin{tabular}{|l|r|r|r|}
\hline Scenario & $\begin{array}{r}\text { EC- } \\
\text { intcgration }\end{array}$ & $\begin{array}{r}\text { Reduced } \\
\text { subsidies }\end{array}$ & $\begin{array}{r}\text { Libera } \\
\text { lization }\end{array}$ \\
\hline High-lech & $0.00 \%$ & $0.00 \%$ & $0.00 \%$ \\
Lab-int & $3.85 \%$ & $2.97 \%$ & $4.30 \%$ \\
Cap-int & $2.90 \%$ & $3.75 \%$ & $4.37 \%$ \\
\hline
\end{tabular}

\subsection{Welfare effects}

Table 4 shows the changes in real GDP in these scenarios. The effects for the non-EC regions are mainly terms-of-trade effects. As net exporters of high-tech goods, North America and Japan lose. NIC and LDC gain due to the price rise for labour-intensive goods, and finally EFTA gains from the rise in the price of capital-intensive goods relative to high-tech products. The EFTA countries import labour-intensive goods, and this reduces the terms-of-trade gain, but the effect is clearly positive. The details of the gains for the EC will be analysed below, but we should notice that the change in trade and industrial policies have substantial impact on the overall gains.

Table 4. Real GDP effects.

(Percentage change from the reference scenario.)

\begin{tabular}{|l|r|r|r|}
\hline Region & $\begin{array}{r}\text { Scenario } \\
\text { integration }\end{array}$ & $\begin{array}{r}\text { Reduced } \\
\text { subsidies }\end{array}$ & $\begin{array}{r}\text { Libera } \\
\text { lization }\end{array}$ \\
\hline EC & 3.40 & 3.98 & 4.59 \\
EFTA & 0.13 & 0.39 & 0.34 \\
N-AMERICA & -0.25 & -0.29 & -0.34 \\
JAPAN & -0.78 & -0.80 & -1.03 \\
NICS & 0.44 & 0.32 & 0.47 \\
LDC & 0.28 & 0.21 & 0.29 \\
\hline
\end{tabular}

6 The developing countries are modelled in the same way as the other regions in VEMOD, i.e. with given and binding resource constraints. One might alternatively assume that the supply of (unskilled) labour is not a constraint in these regions, and that they thus are able to increase production much more than in these scenarios. Neven (1990) shows simulation results for trade in labour-intensive products under the assumption that the EC can impon at given world market prices, and he finds strong structural adjustments between the EC and the rest of the world (and between different EC-countries) for these products. 


\section{EC and EFTA integration}

A set of scenarios in which EFTA takes part in the integration process is shown below. As there are only very few industry studies for the EFTA countries, it is difficult to specify the appropriate productivity shocks for EFTA. Norman (1989a) indicates that the gains for certain industries may be larger for the EFTA countries than for the EC if EFTA takes part in the integration process. However, the number of industries studied is too limited to be useful here; hence, I have applied the same shifts in productivity levels for EFTA as for the EC. If anything, this may underestimate the total effects. Other aspects of integration, like factor movements and so on are not included in the scenarios.

As EFTA is a small region in VEMOD, there are hardly any world market price effects of EFTA joining the integration process; thus it suffices to study the production effects for EFTA. The production and welfare effects for the other regions are insignificant. In fact, the effects for the pattern of production for EFTA are also small; the strong comparative advantage in capital-intensive production continues to be valid through all the experiments, although the size of the high-tech sector tends to go up a little relative to the reference scenario if EFTA takes part in the integration, whereas it was reduced somewhat in the previous scenarios.

\subsection{Welfare effects for the EC and EFTA}

In order to gain insights concerning the pure general equilibrium effects, it is necessary to identify various elements of the total welfare effects for the two regions taking part in the integration process. For this purpose we need a little theory.

Let us look at the budget constraint for a country and simplify by assuming that all goods are traded. Let $E(P, U)$ be the expenditure function for a representative consumer, where $P$ is the vector of world market prices, and $U$ is the utility level ${ }^{7}$. In VEMOD the expenditure function is separable, and can be written $E(P, U)=e(P) U$. $\mathrm{e}(\mathrm{P})$ is the true consumer price index dual to the consumer's utility function. The vector of (compensated) demand functions is given by $c(P, U)=e_{P}(P) U$, where subscript indicates partial derivatives. The supply side of the economy can compactly be represented by the revenue function $R(p, v)$ where $p=P(1+s)$ is the vector of producer prices and $v$ is the vector of factor endowments. $s$ is a vector of subsidy rates; we assume that all distortions are comprised into this ad valorem producer subsidy. As we are going to study productivity changes, it is convenient to introduce a vector of productivity parameters, $\alpha$, in the revenue function, and write $q=\alpha p$, and

7 See e.g. Dixit and Norman (1980) for a thorough discussion of the use of a dual approach in trade theory. In this section we are only concemed with one region at the time: thus the superscript indicating region is dropped for convenicnce. 
$R(p, v)=r(q, v){ }^{8}$ The budget constraint for the economy can now be written:

$$
e(P) U=r(q, v)-s \cdot P \cdot x
$$

Since $r($.$) is measured at the producer prices we subtract the subsidy payments. The$ vector of supply functions, $x$, is given by

$$
x=R_{p}(p, v)=\alpha r_{q}(\alpha p, v)
$$

Totally differentiating (8), using (9) we can decompose the welfare effects of changes in productivity or prices into several elements:

$$
e(P) d U=x \cdot P \cdot \frac{d \alpha}{\alpha}+(x-c) \cdot d P-s \cdot P \cdot x \cdot\left(\frac{d x}{x}-\frac{d \alpha}{\alpha}\right)+r_{v}(q, v) \cdot d v
$$

The first element is the direct effect of productivity improvements - it is the weighted average of the improvements in the sectors. The second element is the terms-of-trade effect on welfare. It is equal to the sum of the price changes, weighted by the (initial) vector of net exports. The third element can be labelled the second-best effect, due to the initial pattern of distortions. Any exogenous change that affects the pattern of production (beyond the direct production effect of the productivity improvements) may change the total distortions and hence the welfare. In brief, this element says that a change that induces increased production of a heavily subsidized activity, yields a negative second-best effect, and vice versa. The change in production, $\mathrm{dx}$, may again be related to changes in the exogenous parameters, using (8). Finally, the last element in (10) takes care of any changes in factor endowments following the exogenous shocks. In our scenario, the only "endogenous" factor endowment is the capital stock, which is endogenous in the sense that with a given savings rate, income growth implies increased total savings and investments. This element will be labelled the dynamic effect, although it comprises only one part of what may be thought of as the dynamic growth effects 9 .

In table 5 the welfare effects for the EC and EFTA are decomposed according to (10), for four of the scenarios: EC integration alone, EC and EFTA integration, integration and reduced subsidies in both regions and finally integration, reduced subsidies and liberalization in both regions, in accordance with the specifications spelled out above.

8 For notational convenience the productivity parameter used here is the inverse of the one introduced in (1) above; hence, $\alpha=1 / a$.

9 Other elements of the new "dynamic growth thcory", like economy-wide increasing retums to scale or endogenous technological development (see e.g. Baldwin (1989)) are ignored here. 
Table 5. Decomposition of welfare effects.

(Percentage change from the reference scenario.)

\begin{tabular}{|l|rrrr|}
\hline $\begin{array}{r}\text { Scenario } \\
\text { Region and effect }\end{array}$ & $\begin{array}{r}\text { EC- } \\
\text { intcgration }\end{array}$ & $\begin{array}{r}\text { EC\&EFTA- } \\
\text { integration }\end{array}$ & $\begin{array}{r}\text { Reduced } \\
\text { subsidies }\end{array}$ & $\begin{array}{r}\text { Libera- } \\
\text { lization }\end{array}$ \\
\hline EC & & & & \\
Productivity & 2.33 & 2.33 & 2.33 & 2.33 \\
Second-best & 0.74 & 0.73 & 1.28 & 1.89 \\
Terms-of-trade & 0.15 & 0.14 & 0.23 & 0.26 \\
"Dynamic" effect & 0.36 & 0.36 & 0.38 & 0.44 \\
Discrepancy & -0.18 & -0.18 & -0.26 & -0.30 \\
\hline Total & 3.40 & 3.39 & 3.98 & 4.62 \\
\hline EFTA & & & & \\
Productivity & 0.00 & 2.20 & 2.20 & 2.20 \\
Second-best & -0.03 & 0.19 & 0.25 & 0.41 \\
Terms-of-trade & 0.14 & 0.14 & 0.26 & 0.27 \\
"Dynamic" effect & 0.02 & 0.30 & 0.31 & 0.34 \\
Discrepancy & 0.00 & -0.13 & -0.13 & -0.12 \\
\hline Total & 0.13 & 2.69 & 2.89 & 3.10 \\
\hline
\end{tabular}

The first row shows the direct effect of the changes imposed, and it should be comparable to the welfare gains from partial equilibrium models. The level of these gains are somewhat lower than the aggregates reported in Emerson (1988); the reason is that the pattern of production in the reference scenario differs from the actual pattern today. In particular the high-tech sectors in the regions are smaller than the present situation, giving a lower weight to the productivity gain in that sector.

The other elements are more interesting, as these are "pure" general equilibrium effects - effects that we have not seen in partial equilibrium analyses. These almost double the direct effects for the EC, and they are strong for EFTA as well. For the EC the most important element is the second-best effect, in particular in the last two cases. The reason is, as we have seen in table 2 , that resources are shifted away from the protected capital- and labour-intensive sectors and towards the less protected, and hence more profitable, high-tech sector. For EFTA the second-best gain is smaller, simply because in these scenarios the pattern of production does not change very much. However, to the extent that the production of capital-intensive goods is based on subsidies and protection, EFTA can increase the second-best gain by unilaterally reducing these subsidies, thereby imposing a different pattem of production.

The positive terms-of-trade effects follow from the fact that both regions are net importers of high-tech goods, for which the relative price goes down substantially. In relative terms the effect means more for the EFTA countries than for the EC. This is also true for the dynamic growth effect; the explanation is simply that the savings rate is higher in EFTA than in the EC, so that any given increase in income yields a stronger growth in the capital stock in EFTA. 
Finally, the discrepancy is due to the fact that (10) is valid for marginal changes, whereas the actual effects studied are fairly substantial. The method of decomposition could have been improved to take care of this; the qualitative picture emerging from table 5 would not have been altered.

\section{2 Factor prices}

The types of shock we study here, are bound to have factor market implications. Shocks that affect goods markets unequally, or shocks that change world market prices, will also affect relative factor prices. Some of these effects are straightforward applications of the Stolper-Samuelson theorem; others are not so obvious. Table 6 shows the real factor price effects in four scenarios, relative to the factor prices in the references scenario. In the last three of the four scenarios, EFTA takes part in the integration and liberalization process. As mentioned above, the structural changes in EFTA in these cases are insignificant.

Considerable care should be exercised in interpreting these results. This is one place where the formulation of the integration as productivity shocks may be misleading. The strong positive effect for skilled labour in the EC in the first case and in EFTA in the second, are standard results from productivity improvements. However, as the productivity shocks in these experiments are meant to include effects through stronger competition and reduced price/cost margins, the actual factor price consequences may differ from the reported ones. In particular, it may be the case that the imperfectly competitive initial situation incorporates elements of monopoly profits in the factor prices; i.e. the wage rate for skilled labour may be too high initially, due to the lack of competition in the goods markets. If that is true, more competitive markets for hightech goods may imply lower wages for skilled labour.

The other effects in the table are more straightforward. For the EC and EFTA these are the combined effects of changes in the domestic support to industries and altered world market prices. For the non-European regions, these are "pure" price effects; however, the effects may differ from Stopler-Samuelson predictions due to the lack of full diversification and the existence of specific factors. 
Table 6. Real factor price effects.

(Percentage change from the reference scenario.)

\begin{tabular}{|c|c|c|c|c|}
\hline Scenario & $\begin{array}{r}\text { EC- } \\
\text { intceration }\end{array}$ & $\begin{array}{l}\text { EC\&EFTA- } \\
\text { integration }\end{array}$ & $\begin{array}{l}\text { Reduced } \\
\text { subsidies }\end{array}$ & $\begin{array}{l}\text { Libera- } \\
\text { lization }\end{array}$ \\
\hline \multicolumn{5}{|l|}{ EC } \\
\hline Rate of return to capital & 0.47 & 0.46 & -1.93 & -4.66 \\
\hline Wage rate, skilled labour & 5.59 & 5.57 & 8.81 & 10.21 \\
\hline Wage rate, unskilled labour & 1.49 & 1.52 & -0.32 & -2.21 \\
\hline \multicolumn{5}{|l|}{ EFTA } \\
\hline Rate of return to capital & 0.34 & 1.33 & 0.77 & -0.50 \\
\hline Wage rate, skilled labour & -0.05 & 3.10 & 2.88 & 2.40 \\
\hline Wage rate, unskilled labour & 0.48 & 2.62 & 2.39 & 1.70 \\
\hline \multicolumn{5}{|l|}{ North America } \\
\hline Rate of return to capital & -0.45 & -0.46 & -0.57 & -0.68 \\
\hline Wage rate, skilled labour & -1.28 & -1.30 & -1.03 & -1.46 \\
\hline Wage rate, unskilled labour & -0.19 & -0.20 & -0.25 & -0.28 \\
\hline \multicolumn{5}{|l|}{ Japan } \\
\hline Rate of return to capital & -0.46 & -0.47 & 1.59 & 2.09 \\
\hline Wage rate, skilled labour & -2.14 & -2.17 & -6.97 & -9.07 \\
\hline Wage rate, unskilled labour & 0.58 & 0.59 & 3.50 & 4.54 \\
\hline \multicolumn{5}{|l|}{ NIC } \\
\hline Rate of return to capilal & 0.41 & 0.43 & 0.21 & 0.41 \\
\hline Wage rate, skilled labour & 0.63 & 0.62 & 0.53 & 0.71 \\
\hline Wage rate, unskilled labour & 0.74 & 0.74 & 0.57 & 0.81 \\
\hline \multicolumn{5}{|l|}{ LDC } \\
\hline Rate of return to capital & 0.65 & 0.63 & 0.44 & 0.69 \\
\hline Wage rate, skilled labour & 0.91 & 0.89 & 0.85 & 1.10 \\
\hline Wage rate, unskilled labour & 0.76 & 0.74 & 0.58 & 0.85 \\
\hline
\end{tabular}

It is worth noting the substantial changes in relative factor prices in the EC and Japan accompanying the structural adjustments. The pattern of these changes can be explained by the Stolper-Samuelson theorem: For Japan the effects come from altered world market prices, with a fall in the relative price of high-tech goods, and an accompanying fall in the wage rate for skilled labour. The opposite is true for capitalintensive goods and the rate of return to capital. For the EC the relative producer price in the high-tech sector increases for several reasons: the direct productivity gain, the reduced support to capital-intensive production and the general liberalization. For all these reasons the wage rate for skilled labour should go up, whereas the rate of return to capital is reduced. The pattern is similar for EFTA; the fact that there are elements of specialization in EFTA's pattern of production ${ }^{10}$ modifies the factor price effects somewhat, compared to those for the EC.

10 EFTA produces all three traded aggregates in these scenarios. The specialization occurs for the production with new-vintage, mobile capital. 


\section{Effects for Norway}

The Norwegian economy is affected by the changing world market conditions and - if Norway joins the integration process - by cost reductions and possibly changes in industrial and trade policies. As discussed above for EFTA, it is difficult to predict exactly how Norwegian markets will be affected, and the analysis shown here simply imposes the same shocks to productivity in Norway as those applied for the EC. The results in this section are taken from the model HOVMOD, in which Norway is modelled as a small, open economy, facing the world market conditions (prices) we have calculated in VEMOD.

The procedure is as for the VEMOD-scenarios. Our point of departure is a reference scenario for the year 2000 in which factor endowments develop along the lines indicated by official sources (for the labour force, see NOU (1988:21)) or recent historical development (for the savings rates), and in which the productivity growth is neutral between sectors and there are no changes in industrial or trade policies (see Haaland (1989) for details). Five cases, representing various degrees of European integration and Norwegian participation will be compared to the development in the reference scenario. Table 7 shows the pattern of industrial production - measured as shares of GDP - in the scenarios, as well as in the initial benchmark situation.

Table 7. Structure of industry in Norway (shares of GDP.)

\begin{tabular}{|l|cc|cc|cc|c|}
\hline Scenario & Benchmark & Reference & \multicolumn{2}{|l|}{ EC\&EFTA integation } & \multicolumn{2}{|l|}{ Reduced subsidies EC\&EFTA } & Liberalization \\
Coods & 1985 & 2000 & Norw. outside & Norw. inside & Not in Norw. & Incl. Norway & Ind. Norway \\
\hline High-tech & 0.06 & 0.03 & 0.00 & 0.03 & 0.00 & 0.13 & 0.13 \\
Labour-intensive & 0.02 & 0.00 & 0.00 & 0.00 & 0.00 & 0.00 & 0.00 \\
Capital-intensive & 0.06 & 0.13 & 0.16 & 0.13 & 0.17 & 0.03 & 0.03 \\
\hline
\end{tabular}

There is a comparative advantage in capital-intensive production in the reference scenario, due to high savings and investment rates. However, in the assumptions there is also strong growth in the share of skilled labour in the labour force, whereas the total labour force grows only moderately. Hence, there is no basis for production of goods using unskilled labour intensively (the labour-intensive sector in the model), whereas there is a potential for skill-intensive production. The cases where Norway takes part in the integration and liberalization process show that changing market conditions may very well yield substantial changes in the industrial structure towards higher production of high-tech goods. In these cases the world market conditions for capital-intensive production are improved (see table 3), but the domestic changes in the pattern of protection dominate the picture.

Welfare effects are shown in table 8 . The procedure applied is the same as for the EC 
and EFTA in table 5. It is interesting to note that the terms-of-trade effect is more important for Norway, and also that the "dynamic" effect is stronger than for the EC and EFTA; the latter point is due to a higher savings rate. The strong second-best effects in the last two cases reflect the structural changes shown in table 7. It is important to note that the structural changes, and thus the substantial positive secondbest effects result from the changes in the Norwegian trade and industrial policies. These could be achieved unilaterally, and joining the European integration is not necessarily a prerequisite.

Table 8. Decomposition of welfare effects for Norway.

(Percentage change from the reference scenario.)

\begin{tabular}{|l|rr|rr|r|}
\hline Scenario & \multicolumn{2}{|c|}{ EC\&EFTA integration } & \multicolumn{2}{|c|}{ Reduced subsidies EC\&EFTA } & $\begin{array}{r}\text { Liberalization } \\
\text { Incl. Norway }\end{array}$ \\
\hline Norw. outside & Norw. inside & Not in Norw. & Incl. Norway & Inctivity \\
Productivity & 0.00 & 2.14 & 2.14 & 2.14 & 2.14 \\
Second-best & -0.24 & 0.10 & -0.27 & 1.16 & 1.28 \\
Terms-of-trade & 0.34 & 0.35 & 0.53 & 0.53 & 0.56 \\
"Dynamic" effect & 0.14 & 0.68 & 0.69 & 0.69 & 0.60 \\
Discrepancy & -0.02 & 0.23 & 0.18 & 0.15 & 0.14 \\
\hline Total effect: & & & & & \\
Real income & 0.22 & 3.49 & 3.26 & 4.66 & 4.71 \\
\hline
\end{tabular}

Table 7 and table 8 reveal that structural adjustments and general equilibrium effects may be very important for Norway. Factor markets will then obviously be affected, and table 9 shows the development in relative factor prices in these cases. As for the factor-price effects for the EC and EFTA discussed above, care should be taken in interpreting the effects of the productivity shock. However, the table indicates that the policy changes are more important than the productivity improvements for Norwegian factor prices, and these effects are more straightforward.

Table 9. Real factor prices.

(Percentage change from the reference scenario:)

\begin{tabular}{|c|c|c|c|c|c|}
\hline \multirow{2}{*}{\begin{tabular}{|lr} 
& Scenario \\
Factor price & \\
\end{tabular}} & \multicolumn{2}{|c|}{ EC\&EFTA integration } & \multirow{2}{*}{\multicolumn{2}{|c|}{$\begin{array}{l}\text { Reduced subsidies EC\&EFTA } \\
\text { Not in Norw. Incl. Norway }\end{array}$}} & \multirow{2}{*}{$\begin{array}{l}\text { Liberalization } \\
\text { Incl. Norway }\end{array}$} \\
\hline & Norw. outside & Norw. inside & & & \\
\hline Unskilled labour & -0.63 & 3.92 & 3.76 & 4.46 & 6.21 \\
\hline Skilled labour & -1.24 & 6.08 & 4.28 & 16.44 & 18.49 \\
\hline Capital & 4.30 & 1.45 & 6.34 & -5.67 & -3.92 \\
\hline
\end{tabular}

Relative producer prices in Norway are affected either by altered world market prices, by altered (relative) productivity, or by changes in relative protection and support; hence, we should expect relative factor prices to adjust in all cases. In table 9 the rate of return to capital tends to increase in those cases where the terms-of-trade effect dominates, whereas the wage rate for skilled labour rises where the productivity improvements or the subsidy reductions are the dominating features. The effects are 
very strong in the last two cases; as the economy is not fully diversified (no labourintensive production), the structural adjustments in these cases require accompanying factor price changes.

\subsection{An alternative specification for Norway}

The structural changes are very strong in the last two cases, and they diverge significantly from the equivalent effects for EFTA shown above. The are several reasons for the differences. First, the assumptions may not be compatible, when it comes to factor endowment in the reference case; this is particularly true for the ratio of skilled labour in the labour force. For Norway I have used official prediction (NOU 1988:21) for the share of skilled labour in the labour force in year 2000 . This implies a very strong growth in the stock of skilled labour in Norway over the period we study; stronger than in the other EFTA countries in the VEMOD scenarios. This may be unrealistic; the effect in the model is that it gives Norway a potential comparative advantage in skill-intensive production.

Secondly, the capital-intensive sector in Norway differs from the one in the average EC or EFTA country. Production in the two models are specified in terms of value added plus input of raw materials and energy. Thus, to measure effective protection we should adjust for the fact that raw materials and energy are internationally traded inputs. As the Norwegian capital-intensive sector is much more energy (and also raw material) intensive than the equivalent sectors in the average EC or EFTA country, a given nominal adjustment in the rate of protection represents a stronger effective shock in Norway. Hence, in the last two cases above, the reductions in the support to the Norwegian capital-intensive sector are in fact stronger than those imposed on the sector in the EC and EFTA.

As an alternative specification the effective - rather than the nominal - rate of industrial support and protection to Norwegian industries have been altered in the scenarios below. The structural effects are shown in table 10, where the last two cases from table 7 are reproduced for comparison. In the reduced subsidies case, the effective producer price in the capital-intensive sector has been reduced by two per cent, while keeping all other effective rates of protection constant. In the liberalization case all effective rates of protection and support are reduced by ten per cent. As expected the structural adjustments are smaller, but the direction of change and the qualitative conclusions remain the same. The table also confirms the impression that the industrial structure is sensitive to the magnitude of the changes in the Norwegian trade and industrial policy. 
Table 10. Structure of industry (shares of GDP).

Alternative specification of reduced subsidies and liberalization.

\begin{tabular}{|l|cc|cc|}
\hline \multicolumn{2}{|c|}{ Sccnario } & \multicolumn{2}{|c|}{ Reduced subsidics } & \multicolumn{2}{c|}{ Libcralization } \\
Goods & Nominal & Effective & Nominal & Effeective \\
\hline High-tech & 0.13 & 0.07 & 0.13 & 0.08 \\
Labour-intensive & 0.00 & 0.00 & 0.00 & 0.00 \\
Capital-intensive & 0.03 & 0.09 & 0.03 & 0.08 \\
\hline
\end{tabular}

Table 11 shows the accompanying welfare effects. As the second-best effects depend on the degree of structural changes, these are obviously modified, and the total gains are thus reduced somewhat. Otherwise there are no substantial differences. The comparison emphasizes that the ability to accommodate structural changes is important to reap the full effects of integration and liberalization. It also points to the fact, already mentioned, that these effects depend on the Norwegian policy changes. In the alternative cases in table 10 and 11 the assumptions for the rest of Europe and the rest of the world are kept unchanged; consequently, the only differences are the magnitude of the Norwegian reductions in industrial support and protection.

Table 11. Welfare effects, alternative assumptions.

(Percentage change from the reference scenario.)

\begin{tabular}{|l|cc|cc|}
\hline \multicolumn{2}{|c|}{ Scenario } & \multicolumn{2}{|c|}{ Reduccd subsidics } & \multicolumn{2}{|c|}{ Liberalization } \\
Effects & Nominal & Effective & Nominal & Effeective \\
\hline Productivity & 2.14 & 2.14 & 2.14 & 2.14 \\
Second-best & 1.16 & 0.52 & 1.28 & 0.76 \\
Terms-of-trade & 0.53 & 0.53 & 0.56 & 0.56 \\
"Dynamic" effcct & 0.69 & 0.68 & 0.60 & 0.59 \\
Discrepancy & 0.15 & 0.22 & 0.14 & 0.23 \\
\hline Total effect: & & & & \\
Real income & 4.66 & 4.09 & 4.71 & 4.27 \\
\hline
\end{tabular}

\section{Concluding remarks}

The purpose of this paper has not been to present yet another set of welfare assessments of 1992; it has been to try to grasp some of the possible general equilibrium effects of European integration. The focus has been on production (and accompanying trade) pattern adjustments in major world regions and on the pure general equilibrium welfare effects.

The direct, "partial equilibrium" gains for various industries are taken from other sources (Emerson (1988)) and these form the basis for the general equilibrium processes that are studied in this paper. The most far-reaching partial equilibrium effects are used. To the extent that these assessments are too optimistic or give a biased picture of the pattern of potential gains between industries, the general equilibrium effects would also have to be modified. 
The world market simulations have been performed in a model with perfect competition and with fairly flexible production possibilities. Hence, we have seen very substantial structural changes, in particular between the EC and Japan. Imperfect competition may reduce this flexibility; "more concave" production possibility frontiers (e.g. due to specific factors), or active use of industrial policies may also dampen the flexibility. To the extent that the structural flexibility is lower than in these scenarios, the terms-oftrade effects will increase. It is, however, worth noting that although the reported structural effects of 1992 are strong, they tend to reduce the need for structural adjustments indicated in the reference case. Perhaps the 1992-programme could be regarded as a attempt by the EC to maintain a diversified structure of industry and to avoid too much specialization in protected, capital-intensive production?

The welfare decompositions in tables 5, 8 and 11 reveal that there are interesting general equilibrium consequences of European integration. For a country like Norway, with a strong specialization in capital-intensive sectors, the direct productivity gains are moderate, but the terms-of-trade effects are substantial. The second-best effects following the structural adjustments are the most important general equilibrium elements both for the EC and for Norway. These reflect the initial pattern of protection and industrial support; two points should be emphasized here. The first is that the second-best gains depend on the structural flexibility; to the extent that this is exaggerated in the models, the same is true for the second-best gains. On the other hand, a less flexible structure worldwide would probably increase the terms-of-trade gains for Europe. The second important point to make regarding the second-best effects, is that these very much depend on the domestic industrial and trade policy. Reduced subsidies and liberalization are natural parts of European integration, but integration is not a prerequisite for these policy adjustments to take place.

And in particular, a small economy, like Norway, could achieve these results by unilateral action, with no need for international cooperation or integration. If this is not done, it must be for political reasons. And this is perhaps the strongest case for taking part in the European integration process: it makes it easier, politically, to achieve the domestic policy changes and structural adjustments that are needed in any case. 


\section{REFERENCES}

Baldwin, Richard (1989): The growth effects of 1992. Economic Policy, October, pp. $245-281$.

Dixit, A. and Norman, V. (1980): Theory of international trade. Cambridge University Press.

Emerson, M. (1988): The economics of 1992. Oxford University Press.

Haaland, Jan I. (1989): Modelling general equilibrium in a small, open economy: A Norwegian example. Centre for Applied Research. report no. 11/89, Bergen.

Haaland, Jan I. (1990): Assessing the effects of EC-integration on EFTA countries: the position of Norway and Sweden. Journal of Common Market Studies, vol. XXVIII, No. 4, June, pp. $379-400$.

Haaland, J, and Norman, V(1987): EFTA and the world economy. Comparative advantage and trade policy. EFTA Occasional Paper no. 19.

Haaland, J., Norman, V., Rutherford, T. and Wergeland, T (1987): VEMOD: A Ricardo-Heckscher-Ohlin-Jones model of world trade. Scandinavian Journal of Economics, Vol. 89, no. 3, pp.251 - 270.

ILO (1986): Labour force estimates and projections, Geneva.

Neven, Damien J. (1990): EEC integration towards 1992: some distributional aspects. Economics Policy, April, pp. 14 - 46

Norman, V. (1989a): EFTA and the internal European market. Economic Policy, October, pp. 423 - 465 .

Norman, V. (1989b): Imperfect competition and general-equilibrium aspects of trade. Typescript, Norwegian School of Economics and Business Administration, Bergen.

NOU 1988:21: Norsk okonomi i forandring. Perspektiver for nasjonalformue og $\emptyset$ konomisk politikk i 1990-ärene. Ministry of Finance, Oslo.

Smith, A. and Venables, A. (1988): Completing the internal market in the European community: Some industry simulations. European Economic Review, vol. 32 , no. 7 , pp. $1501-1525$. 


\section{APPENDIX}

Classification of traded goods in the benchmark data for VEMOD. The classification for HOVMOD is similar, but with some differences (see Haaland (1989)).

Raw materials (including agricultural products) and oil are defined as usual. Traded final goods comprise the following:

High-tech (skill-intensive) products:

Chemicals (ISIC 351-352)

Non-metallic mineral products (ISIC 362, 369)

Machinery (ISIC 382)

Electrical, professional and scientific equipment (ISIC 383, 385)

Transport equipment except ships (ISIC 384 except 3841)

Labour-intensive products:

Textiles, clothing, footwear (ISIC 321-324)

Wood and paper products, except pulp and paper (ISIC 331, 332, 341 except 3411)

Printing and publishing (ISIC 342)

Rubber, plastic and china products (ISIC $355,356,361$ )

Fabricated metal products (ISIC 381)

Shipbuilding (ISIC 3841)

Capital-intensive products:

Food and related products (ISIC 311-314)

Pulp and paper (ISIC 3411)

Petroleum products (ISIC 353-354)

Basic metals (ISIC 371-372)

For the EFTA countries, merchant shipping is also included among the capital-intensive industries. For the other regions, shipping is an insignificant industry and has therefore been ignored. 